\title{
The relationship between mathematical content knowledge and mathematical pedagogical content knowledge of pre-service primary teachers
}

\section{Stephen Norton}

\author{
Griffith University
}

s.norton@griffith.edu.au

\begin{abstract}
In Australia there is increasing scrutiny of teacher education processes in learning to teach primary mathematics. In this study mixed methods, including linear regression, are used to examine the entry mathematical content knowledge of third-year Bachelor of Education Pre Service Students and to relate this to their graduating level of content and a measure of pedagogical content knowledge based upon capacity to describe student errors and provide learning support. The data indicate low levels of mathematical content knowledge at the beginning of the course, prompting questioning of the focus of earlier mathematics curriculum courses. Over the life of the study there was improvement in some domains, which is to be expected if knowledge of mathematics was an intended outcome. Mathematical content knowledge at the start, but particularly at the end of the study, was highly predictive of expressions of mathematical pedagogical content knowledge. The stronger predictive value of mathematical content knowledge for mathematical pedagogical content knowledge suggests merit in developing the two aspects of teacher knowledge in tandem, rather than in different courses. The relevance of the data to teacher preparation in the institution and more broadly is discussed.
\end{abstract}

Key words: teacher, mathematics, content, pedagogy, knowledge

\section{Introduction}

Hattie's (2009, p. 111) meta-analysis relating to teacher education shows that "the size effect of teacher education on subsequent achievement is negligible". Such deflating statements prompt a desire to check the validity of this at a local level, and if the assessment has some validity, to determine how the processes of teacher preparation can be enhanced. Of course, this starts from a deficit assumption and the author is aware of the potential that "documenting the deficiencies of novice teachers and students [can] contribute[s] to the general malaise of teaching and learning mathematics as inadequate...” (Mason 2016, p. 298). The view that is taken in this study is that critical analysis of pedagogical acts in teacher preparation courses warrants investigation, but it is acknowledged that some pre-service teachers and indeed teacher educators will feel uncomfortable with this process. Others may well feel empowered by it.

In recent decades, teacher knowledge of mathematics has become a key area of focus for the improvement of children's academic outcomes in mathematics. Underpinning the promotion of teachers' knowledge of mathematics is the simple notion that teachers who know more mathematics are likely to teach it better. In England, Burghes and Geach (2011, p. 17) reported, “A prerequisite to be an effective teacher of mathematics, is that you are confident and competent in mathematics at a level significantly above that which you are teaching." Similarly, the Teacher Education and Development Study in Mathematics (TEDS-M) (Tatto et al. 2008, p. 19) noted, "Knowledge of content to be taught is a crucial factor in influencing the quality of teaching." 
Goldsmith, Doerr and Lewis (2014) summarised much of the then available research on teachers' mathematics content knowledge (MCK) and noted a lack of it can impede teachers' abilities to notice and analyse students' thinking as well as their ability to engage in productive professional conversations. Gess-Newsome (2013, p. 258) suggested, "Teachers content knowledge for teaching mathematics (CKT-M) significantly and positively predicted student achievement ... The only variable that approached CKT-M in explaining student achievement was students' socioeconomic status.”

The relationship between knowing mathematics and teaching mathematics has a long history and the theoretical understanding of the nuances underpinning the relationship is being continually refined. Shulman (1987) noted seven forms of knowledge as a basis for teaching: content knowledge (MCK), pedagogical knowledge, pedagogical content knowledge (PCK), curriculum knowledge, knowledge of students, knowledge of educational contexts, and knowledge of purposes of education. Shulman considered that subject matter (MCK) was the set of concepts, fundamental assumptions, definitions and procedures that must be learned. PCK included the forms of representations of content knowledge, analogies, examples, models, and explanations of the mathematics that make the learning of the content understandable or, alternatively, difficult. Curriculum knowledge was considered to be an understanding of how mathematical topics were arranged and connected across school experiences. Many scholars have subsequently used Shulman's categories of knowledge and refined them to various degrees, adding further descriptions or coining new anachronisms and insights (e.g., Ball and Bass 2000; Delaney, Ball, Hill, Schilling and Zopf 2008; Ball, Thames and Phelps 2008; Beswick and Goos 2012; Chapman 2015; Jacobson and Kilpatrick 2015; Zhang and Stephens 2013). In considering mathematics teaching and learning, adding M to PCK refers to pedagogical knowledge specific to mathematics; thus, mathematics pedagogical content knowledge (MPCK) (Dohrmann, Kaiser and Blomeke 2012). In this paper the term MPCK is used in the same sense as Gess-Newsome (2013) defined PCK. That is, it embraces (a) content knowledge (including depth, breadth and accuracy of content knowledge, connections within and between topics, and the nature of the discipline as well as fluency with multiple modes of representation); (b) pedagogical knowledge (including a rationale linking teaching strategies to learning, strategies for eliciting prior understandings, and strategies to promote meta-awareness among students); and (c) contextual knowledge, which includes understanding students' prior conceptions. Beswick and Goos (2012) earlier noted the "interconnectedness of (MCK) and PCK and the difficulty in distinguishing between them" (p. 72).

\subsection{Aims and purposes}

The importance of knowing the mathematics to be taught is well documented. Empirical evidence on the depth of mathematical knowledge of primary or elementary pre-service teachers (PSTs) in Australia is less well documented. Thus, the first aim of the study was to examine the MCK of pre-service teachers who had already completed two mathematics curriculum courses (Mathematics 1 and Mathematics 2). Their stage in their teacher preparation studies is particularly relevant to the structuring of the program within the university, and in particular the structuring of the final mathematics curriculum course (Mathematics 3). As outlined in the introduction above (and expanded upon in the more extensive review below) it is clear that a complex relationship exists between MCK and MPCK. Thus the second aim of this paper is to provide statistical data on the nature of that relationship. Collecting data on MCK at the commencement and at the end of Mathematics 3, and on MPCK at the end of Mathematics 3, enables us to examine the relationships between MCK and MPCK and to trial alternative methods of assessing MPCK. As noted earlier, international studies including those by Beswick and Goos (2012), Burghes and Geach (2011), Tatto et al. (2008) and Krainer et al. (2015) described pre-service teachers' MCK and broad conditions of learning, but did not relate these to specific interventions intended to develop MPCK. The third aim of the paper, then, is to provide detail on the form of the intervention. This enables teaching academics to decide if the intervention methods have any place in their own teacher education preparation programs. 


\section{Literature review}

\subsection{The role of mathematical content knowledge in teaching primary mathematics: Different perspectives}

Shulman's (1987) original studies involved secondary school teachers; he recognised that teaching elementary or primary children and preparing to do this had different challenges. This study is concerned with the preparation for the teaching of mathematics by primary teachers. Most teachers of primary mathematics in Australia and elsewhere (e.g., United Kingdom, United States of America, New Zealand) are not specialist teachers of mathematics, but rather are generalist classroom teachers who teach a range of subject disciplines including English, science, humanities and mathematics.

A factor that is cited as evidence for the link between teachers' MCK and teaching capacity is the high performance on international tests of East Asian nations. This is evident in tests including Trends in International Mathematics and Science Study (TIMMS) and Programme for International Student Assessment (PISA) (Mullis, Martin, Foy and Arora 2012; Organization for Economic Co-operation and Development [OECD] 2014). The test data indicate that East Asian nations have relatively high proportions of students reaching international benchmarks compared to Western nations including Australia, England, the US, and New Zealand (Mullis et al. 2012). Supporters of improving pre-service teachers' MCK have noted the emphasis that top-performing nations have placed on this element: prior to teacher training, during the process and after graduation. For example, at the primary level, Krainer, Hsieh, Peck, and Tatto (2015) have reported the superior MCK of future teachers in East Asia, including Taiwan and Singapore, over the US. Similarly, Burghes and Geach (2011) reported the superior MCK of Chinese and Japanese trainee teachers compared to their peers in England, Ireland and Finland. It needs to be noted that the prevailing recommendations for mathematics pedagogy are culturally sensitive. In East Asia, primary teachers of mathematics play the role of guide, and instruction is teacher dominated with student control minimal (Leung, Park, Shimizu and Xu 2015). The East Asian valuation of breadth and depth of mathematics content is summed up as follows: "A profound understanding of elementary mathematics and strong problem solving abilities in this field are crucial to becoming a qualified mathematics teacher” (Leung et al. 2015, p. 129).

It is hardly surprising that East Asian teacher preparation programs reflect the underlying belief that mathematics content is a critical aspect of teacher competency. This belief is manifested in their program structures and the extended time which pre-service primary teachers are afforded to learn pure mathematics as MPCK (e.g., Norton and Zhang 2016; Qian and Youngs 2016). Tatto, Rodriguez and Lu (2015) found that across countries, individual teacher preparation program characteristics have a similar and powerful influence on what teachers come to know at the end of their pre-service programs. In particular, and importantly for the West, the most positive influence in MPCK was found to be the "opportunity to learn school level mathematics" (Tatto et al. 2015, p. 313). Building on the importance of what mathematics might be specifically useful to primary teachers, a growing number of researchers are focusing on teaching for both understanding and mathematical fluency at a relevant level of abstraction. This position is supported by Hattie (2009) who contended that subject matter knowledge was of minimal importance beyond some level of basic competency. That is, knowing differential calculus will not be of much help in teaching subtraction of whole numbers, and may even be a hindrance (hence the effect size of 0.09 [Hattie 2009, p. 114]).

\subsection{Basic content and epistemology}

ACARA (2017a, p. 1) uses the term "numeracy" as an organising principle and defines it thus:

"Numeracy encompasses the knowledge, skills, behaviours and dispositions that students need to use mathematics in a wide range of situations.” The important aspect of this definition for this paper is the need to apply mathematical skills or knowledge to particular contextual situations. At the primary level, this generally means the children have to decide what particular skills or computations are needed prior to setting about computations. Similar to the national testing of children through National Assessment Program, Literacy and Numeracy (NAPLAN), the testing of pre-service teachers' knowledge of mathematics is frequently done in 
particular contexts; thus, the pre-service teacher first has to decide on the appropriate computations or procedures then accurately enact them. In this paper, MCK includes these two cognitive aspects of numeracy: knowledge and skills in a wide range of situations.

Reviews of the MCK of pre-service and in-service teachers internationally (e.g., Norton and Zhang2016; Beswisk and Goos 2012; Burghes and Geach 2011; Delaney et al. 2008; Krainer et al. 2015; Ma 1999; Qian and Youngs 2016; Tatto et al. 2008) have suggested that when compared to top nations (e.g., China, Singapore, Korea, Japan, Russia), much of the English speaking West (e.g., Australia, New Zealand, England and the US) have placed less emphasis on the mastery of learning basic facts and processes (such as capacity to carry out whole-number and fraction computation) by pre-service teachers. This is clearly evidenced in substantially lower scores in tasks involving straightforward computations and processes. More local studies, such as Ingram and Linsell (2014) and Major and Perger (2014) indicated that in New Zealand, some institutions were aware that significant portions of pre-service teachers lacked necessary mathematics content and these institutions were making a concerted effort to pre-test and take account of this lack. In Australia, Beswick and Goos (2012) and Livy and Herbert (2013) cautioned about making assumptions with regard to pre-service teachers understanding key skills and concepts. Hine (2015) makes a similar comment, stating that Australian universities have largely assumed that trainee teachers will enter competent in the mathematics content, while in fact many had content-related problems that stemmed from their personal inadequate primary mathematics experiences.

Recent trends illustrate a refinement with respect to the threshold of fluency and understanding needed to teach at the primary level. Beswick and Goos (2012) reported that the TEDS-M test of MCK categorised items according to difficulty from novice (content taught at the grade level to be taught by the future teachers) to intermediate (one or two years in advance of the grade level to be taught by the future teacher) and advanced (three or more years beyond the grade level anticipated to be taught). Their view was that the relevant threshold of content included “approximately even coverage of the curriculum content from foundation to Year 7” (p. 76). If the threshold of MCK for pre-service primary teachers is at the novice level (up to Year 7) it might be reasonable to assume that almost any pre-service teacher who has completed 12 years of schooling (i.e., current undergraduate degree entry) or a relevant undergraduate degree (graduate diploma degree entry) would pass this threshold. Burghes (2008) and more recently Qian and Youngs (2016) claim that such a "tick the box" mentality has been used as a proxy for making inferences about MCK prior to and post pre-service teacher education. The authors above considered that such box ticking, including counting the number of courses completed prior to and during teacher education, was a flawed metric that had the potential to diminish the effectiveness of teacher preparation programs.

Henderson and Rodrigues (2008), Hine (2015) and Kotzee (2012) reported that it has become a tradition in teacher education courses at Western universities to focus on big-picture curriculum issues including thinking skills, problem-solving and team work, and to largely assume that PSTs have a basic knowledge of content. The motives for such a generic approach to teacher preparation are complex. A number of authors (e.g., Graven 2002; Hattie 2009; Meyers 2012; Muller 2000; Stipek, Givvin, Salmon and MacGyvers 2001; Young 2011) have claimed that the rationale derives from the dominant epistemology for education in the English speaking West, including in Australia, that has been termed "constructivist" and "social-constructivist". It is noted that non-mother tongue nations including Czech Republic, Finland, Hungary, Russia, (Burgher \& Geach, 2011) and Germany (Kleickmann, Richter, Kunter, Elsner, Besser, Krayss and Baumert, 2013) tended to have teacher education programs that placed significant emphasis on prospective teachers knowing the content they were preparing to teach. Young (2011, p. 268) claimed, "the teacher becomes a facilitator of learning and the distinctiveness of pedagogic relationship between teacher and pupils in providing students with access to specialist knowledge is played down." It needs to be noted that pedagogy consistent with constructivist epistemology is strongly recommended by the National Council of Teachers of Mathematics (NCTM) (2014, 2015); according to Wilson, Cooney and Stinson (2005), this has been the case for some decades. NCTM-like recommendations in curriculum guidelines are found in most Western mathematics curricula, including Australia (Australian Curriculum, Assessment and Reporting Authority [ACARA] 2012). The claim is that the epistemology underpinning constructivist pedagogy (also called inquiry-orientated pedagogy and termed 
minimum guidance by Kirschner, Sweller and Clark 2006) has been used to justify placing increased responsibility and freedom for learning on children and a greater focus on generic principles of learning (Young 2011). Yet depth of knowledge in teachers is essential, according to Chen, Kalyuga and Sweller (2016, p. 28), who reported, "for the learning of complex materials, explicit instruction is essential for novice learners". Needless to say, it is difficult to be effective in enacting explicit instruction if the teacher has a limited understanding of the material, something of which the father of social-cultural principles, Vygotsky, was well aware. Thus, the authors above have argued that constructivist thinking has become associated with a deemphasis on the need for depth of formal mathematics knowledge in teachers. Poulson (2001), in support of the stance of rejecting overemphasis on formal knowledge of mathematics, has pointed out that teachers can learn the critical tacit knowledge with the children, on the job while facilitating classroom discourse.

Whether there has been a trend in teacher preparation to de-emphasise pure knowledge of mathematics or not, the presumption that such a pattern exists has attracted the criticism of cognitive load theorists (e.g., Kirschner et al. 2006; Owen and Sweller 1989) whose view is that mathematics is a hierarchical body of knowledge and basic facts and processes underpin more advanced problem solving. In other words, mathematics conforms to the vertical as distinct from horizontal organization of knowledge (Bernstein 1999, 2000; Muller 2000, 2009; Muller and Taylor 1995). Recently, Hattie and Donoghue (2016) argued the retention of accurate detail (surface learning), then lower-level learning, is a necessary foundation to higher level problem solving and creative thought. This positon is supported by the OECD (2014) and Klein (2005). Bernstein (1999) contended that access to systematically structured, hierarchically organised knowledge forms affords social advantage to those who have the opportunity to access it.

Pre-service teacher education institutions publish brief descriptors of the nature of their courses; in Australia, these are called course profiles. Some indication of the priorities of teacher preparation institutions is contained in these publications. Course profiles invariably make some statement to the effect that pre-service teachers will learn the necessary mathematics and pedagogy to function in classrooms. Such documents usually also reveal the time and mode allocated for learning, which can range from entirely online with no access to face-to-face learning from the expert teacher educator, to about 40 hours of face-to-face learning in a 10-credit point curriculum course. Typically, Australian pre-service primary teachers might be offered two or three such mathematics curriculum courses. It is very rare that the tertiary institution publishes the detail of examinations or samples of past papers; thus, we have an assurance that standards will be delivered, but little evidence of what those standards might be. Arguably the means by which teacher preparation courses account for linking of content and pedagogy is not easily discerned by actors outside of the particular institution. One aim of this paper is to provide transparency, at least with respect to one mathematics curriculum course.

\subsection{Research questions}

The following research questions were posed:

1) What was the starting MCK of third-year PST and how was this related to their MCK at the end of the course which was just prior to graduation?

2) How was MCK related to MPCK at the end of the course?

By looking at estimates of both starting MCK and at the end of the course MCK and the relationship between these, and at measures of MPCK, we can gain some insight into the effectiveness of the intervention as well as the relationship between MCK and MPCK.

\section{Method}

\subsection{Overview}


The research design has two aspects to it. The first is experimental, in that the effect of an intervention is assessed. The second aspect of the design is correlational, in that the relationships between starting MCK and post-intervention MCK and MPCK are examined.

\subsection{Subjects}

The university in which the study was undertaken is ranked in the top 3\% of universities globally (World Universities Ranking 2017) and the school of education was ranked in the top 100 globally (School of Education and Professional Studies 2017). The program and course were in full compliance with standards set by the Queensland College of Teachers (QCT), the statutory body that accredits programs and teachers in the state. The subjects were third-year undergraduate primary education students enrolled in their third and final capstone mathematics curriculum course. In this cohort a total of 150 students were sampled at the commencement of the course in the second semester of 2015. This represented 74\% of total enrolments. For the remaining $26 \%$ there were insufficient data to pair the pre-post test results, perhaps because students did not identify themselves legibly on the pre-test, or because they did not sit the pre-test, or did not consent to the use of data from surveys and tests at the outset of the study. There is no reason to believe the sample is not representative of the cohort; in fact, means for the unnamed students were identical to the reported sample.

\subsection{The intervention}

The intervention was the scheduled final mathematics curriculum course of this cohort. The guiding pedagogical approach was dominated by explicit instruction to take account of cognitive load theory (eg., Chen, et al., 2016; Krischner et al., Sweller, 2016).

Mathematics 3 was run over 8 weeks, with 2 hours of lectures that were lecture captured (video recorded and available online) and 2 hours of workshops each week. The assessment included a 50\% research-based assignment where students carried out a case study on a primary school student. Such a project gave the preservice teachers the opportunity to deeply explore the teaching of one or two key mathematics concepts. The remaining $50 \%$ of the assessment was a closed-book 3-hour examination; the results, for those students who consented to participate in the study, are reported in this paper. Thus, the assignment helped develop a narrow range of pedagogies while the examination assessed a spread of mathematical concepts and pedagogy. Consistent with the tertiary provider's assessment policy, the two percentages were added.

The main resource used to support this course was 16 hours of explicit DVD-based material (with 500-page pdf booklet; Norton, 2014). The intervention approach was to attempt to develop MCK and MPCK simultaneously and use examination of children's thinking as the starting point. Adler and Davis (2006) reported that it was possible to produce a correct solution by following a set of learned steps without understanding their significance. The intervention attempted to take account of this challenge. The critical role of understanding student thinking prior to planning has wide and enduring support (e.g., Beswick and Goos 2012; Callingham et al. 2012; Gess-Newsome 2013; Hattie and Donoghue 2016; Reisman 1978; Tatto et al. 2008). Part of the process of understanding a learner's thinking can include error pattern analysis, and this has been used previously (e.g., Chick, Pham and Baker 2006; Marshman and Porter 2013; Reisman 1978). Gess-Newsome (2013) considered examining student work or misconceptions as a "particularly effective means of increasing teachers' careful consideration of content and pedagogical knowledge on classroom practice...” (p. 258). Consistent with Hattie's (2009) recommendation for clarity in planning, specific meaningful language was used to connect material and model proofs to symbolic representations, an approach recommended by numerous educators including Booker, Bond, Sparrow, and Swan (2010) and Hill, Rowan and Ball (2005). The appropriate and sequential use of materials and models in the teaching of mathematics is widely recommended in teacher education texts (e.g., Bobis, Mulligan and Lowrie 2004; Booker et al. 2010; Sonnabend 1993; Van de Walle 2007) and these and other sources texts were drawn upon to prepare the intervention.

The resources developed by the author to support the intervention, indeed the entire delivery of the course, depict an image of mathematics as essentially vertical (Bernstein 1999, 2000; Graven 2002; Muller 2000, 2009). 
The vertical nature of mathematics is also the primary arranging tenet of the Australian Mathematics syllabus. That is, whole-number addition and addition facts are learned before subtraction and this precedes multiplication which of course precedes division concepts, facts and processes. It is anticipated by the Australian syllabus that children have understanding of and fluency with whole-number computation prior to learning fraction computation and so on.

Typically, the lecture or workshop activity commenced with the analysis of a school student's work such as exemplified below. There are multiple sources of student error patterns including the teacher education texts books noted above, local tests, and tests collated in the resource support for the course (Norton,2014). Several examples of this process are illustrated below.

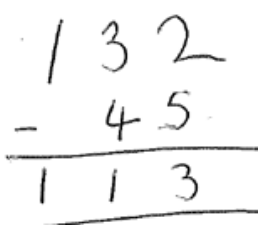

Figure 1. Sample of a Year 3 student's work for the question, John had 132 marbles and Luke had 45. How many more marbles does John have? What thinking is demonstrated and explain how you would go about providing learning support.

Since the problem is set in a contextual setting it is by definition a numeracy problem. A subtraction problem of this structure was used in the NAPLAN Year 5 and 7 tests (Question 13) (ACARA, 2014b) where the national success rate across the nation was $69 \%$ in multiple choice format. A comparison subtraction in decimal format (3.14 metres take away 1.25 metres and express the answer in centimetres - Question 39) had a 15\% success rate for written response format. For both questions the Queensland success rate was similar (66\% and 13\%) to the national, illustrating the correlation between Queensland scores and national averages and also illustrating that subtraction difficulties are prevalent among Australian children several years after the concepts and processes have been introduced.

In the example in Figure 1 it was anticipated that the pre-service teachers would acknowledge that the child correctly recognised that the appropriate operation was subtraction, since this is an example of "compare" context, the other two contexts being "missing part" and "take-away". The error in thinking is likely "big number take away small number" and this may have resulted from lack of clarity in the use of instructional language and/or failure to develop the subtraction concept and operation with material representations. Learning support would likely include using base-ten materials to revise renaming (regrouping) on a place-value chart. This could be followed by developing the subtraction algorithm first with bundle sticks on a tens and ones place-value chart then subsequently with base-ten materials on a hundreds, tens and ones place-value chart. Clarity in the use of language would include, "We have two ones, can we take away five ones? No? Therefore rename one 10 into 10 ones and now there would be 12 ones..."

The teaching of multiplication is a major undertaking in middle primary years and frequently challenging. For example, the 2014 Year 7 NAPLAN numeracy (non-calculator) test had the multiplication question, “Anna's family spends $\$ 120$ a week on groceries. How much does her family spend in 52 weeks?” (ACARA 2014a, p. 9). As was the case with subtraction, the contextual setting justifies branding this problem as a numeracy problem since the children have to decide on the appropriate computation. In written response format the Queensland success rate was 45\%. The question above can be viewed as 12 by 52 then multiply by 10 . Stimulation such as that represented below was one of many used to stimulate pre-service teachers' thinking about teaching multiplication. This particular error pattern was published by Norton (2012). 

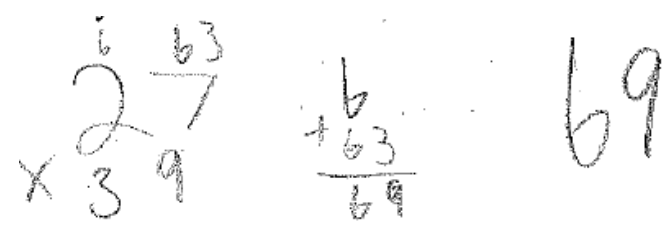

Figure 2. Student multiplication of two-digit numbers (27 by 39).

A possible explanation for the child's work above is that the child has multiplied 7 by 9 and recorded 63, then 2 tens by 3 tens and recorded 6 tens and subsequently added 6 and 63 to gain a solution of 69 . The script contains evidence of good number facts but of shallow place-value understanding (tens by tens are hundreds, not tens as recorded) and the child has failed to cross multiply. The learning support would likely include revision of place value and linking the vertical traditional algorithm to an area model to emphasise cross multiplication.

Brown and Quinn $(2006,2007)$ detailed student difficulties with fractions and noted they were widespread. The student error below prompts reflection on the teaching of fraction multiplication.

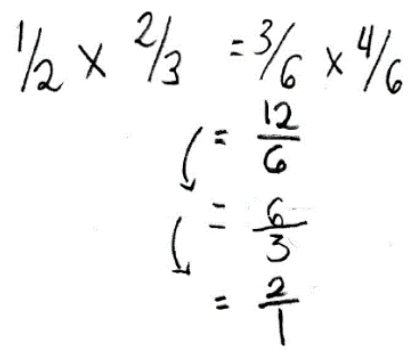

Figure 3. Sample of student work on fraction multiplication.

The problem in Figure 3 is not a numeracy problem as there is no context. Only fluency of computation is required. In the example the pre-service teacher would be expected to recognise that the child had confounded fraction addition and multiplication processes. That is, they sought a common dominator in the first instance, multiplied the numerators and retained the common denominator then reduced this by dividing by common factors. Learning support would likely include the use of area models to illustrate the multiplication of fractions, such as illustrated by Van de Walle (2007, p. 325).

With respect to the final examination (50\% of grade mark) the author considered Hattie's (2009) and Hattie and Donoghue's (2016) advice of knowing the success criteria; thus, the pre-service teachers were given access to earlier summative tests of similar courses offered by the author. This gave them the opportunity to become familiar with the course expectations in terms of the depth and forms of knowledge expected and nuances of assessment format. Access to earlier summative tests could potentially create a ceiling effect since the question structures of past papers were very similar to the summative test used with this cohort. Of course the manifestation of a ceiling effect would likely depend on the pre-service teachers understanding the underpinning concepts such that they could apply the knowledge in modified contexts.

\subsection{Instruments}

\subsubsection{Starting MCK}

Starting MCK was assessed in the first workshop where students were given a 45-minute author-designed test of fundamental content. The test was written response, closed book and calculator free. The decision not to use multiple choice format was because the author considered written solutions had the potential to reveal more detailed information such as how the pre-service teachers set out their work and where they may have made errors. This approach also circumvented guessing and elimination strategies such as substitution of given responses into the test item. Further, the ACARA syllabus requires children to apply "efficient mental and 
written strategies and appropriate digital technologies to solve all four operations..." (ACARA, Year 6 Content Descriptions, 2012). The limited use of calculators in the course, and subsequently in the assessment, is consistent with Hattie's (2009) summary that the use of calculators is most productive when used to check answers, to reduce cognitive load when problem solving, and for specific pedagogical purposes. Further, if numeracy at this level has essentially two elements -- deciding on the appropriate computation and then fluency with the computation -- the lack of access to a calculator places greater emphasis upon computational fluency. Calculator use in schools has been strongly recommended for some decades, for example the Australian Association of Mathematics Teachers (1996) stated; “Access to a basic calculator is required for All students as a most significant means for intruding and developing number sense" (p. 4). Clearly the author did not share this confidence in the prevalent early use of such technology.

The starting test had two components. Part A drew heavily from Burghes's (2008) international comparative study in mathematics teacher training (ICSMTT), the Trainee Teacher Primary Mathematics Audit. The author added a few whole-number computation questions. Part B, the author-constructed test, drew from material used in NAPLAN numeracy tests (Ministerial Council on Education, Employment, Training and Youth Affairs [MCEETYA] 2014-2015). The test evaluates student mathematical competency in whole number, computation, fraction computation, proportional reasoning, algebraic thinking and problem solving with these cognitive tools. Consistent with the tests used by Qian and Youngs (2016) and recommended by other authors (e.g., Beswick and Goos 2012; Burghes and Geach, 2011; Chick et al. 2006; Livy and Herbert 2013) the test items were approximate to the level of mathematics to be taught by the pre-service teachers. That is, test items, with few exceptions, were at a level that correlates to novice on the TED-M classifications.

An example of a novice question is Question 1 of the pre-test is as follows:

John needs to save $\$ 40,000$; so far he has saved $\$ 2,379$. How much more money does he need to save? (Pre-test success rate 69\%)

This problem is a numeracy problem and no pre-service teacher failed to recognise that the required operation was subtraction; they erred in their capacity to enact the algorithm. A subtraction question of this nature assesses fluency with number facts as well as ability to carry out the computation. The method of renaming, in which the student carried out the process by renaming 4,000 tens to 3,999 tens and 10 ones, or did the renaming in steps, provided detail that would be used to refine the intervention. Regrouping (or renaming) to tens of thousands is consistent with Year 4 content descriptions (ACARA 2012). Question 2 (below) involved multiplication of a 3digit by a 2-digit number (pre-test success rate 45\%) and Question 3 assessed if the pre-service teachers were fluent in number facts and could carry out the division algorithm that is consistent with Year 6 ACARA (2017) content descriptions.

A syndicate of 27 girls shared $\$ 455$ between them. How much was each share to the nearest cent? (Pre-test success rate $11 \%$ ).

In the marking of test items such as the above, full marks (1) would be allocated for a correct solution, 1 half mark would be allocated if the pre-service teacher made a minor calculation error such as one number fact mistake, and zero marks would be allocated if there was more than one computational or number fact error, or if it was clear the subject did not have a mathematically correct strategy. An example of lacking a suitable strategy for Question 3 would be an attempt to apply the short division algorithm to the problem.

\subsubsection{Post-intervention MCK and MPCK}

The instruments used to collect these data were the tests used to assist in the grading of students at the end of the course. The test was a closed-book examination over 3 hours. Part A was designed to test MCK and MPCK that were a focus of the course. A sample question is provided in Figure 4.

There were some cars parked in the sale yard. 1 third were Toyota; 1 half were Mazda and the remaining fraction were BMW cars. What fraction were BMW cars? 


\section{$\frac{1}{3}+\frac{1}{2} \Rightarrow 1-\frac{2}{5}=\frac{3}{5}$}

(a) If there is an error, describe it here. (MPCK-1 mark)

(b) Write the correct solution. (MCK-2 marks)

Figure 4. Sample of test of pre-service teacher’s ability to describe student thinking (diagnosis) MPCK and MCK.

In the marking of the first part of the question (a), a full mark would be justified if it was judged that a reasonable insight had been shown, for example that the student had recognised that a subtraction was required, but had made a conceptual error in adding one third and one half as whole numbers to two fifths, thus treating the fractions as whole numbers. If the pre-service teacher simply reported that no error had been made or did not describe an evidence-based error, no marks were allocated. The question structure is similar to those reported by Tatto et al. (2008) where the process is described as "analysing or evaluating mathematical solutions or argument” (p. 72).

Part (b) "Write the correct solution" was allocated full marks if the solution was correct. Part (b) solutions also gave insight into how the pre-service teachers went about solving the problem, but this aspect was not assessed.

There were 25 questions in Part A of the post-test; 11 of the MCK questions were identical in structure to questions in the pre-test of MCK. This overlap enabled the improvement in capacity over the intervention on same tasks to be plotted. As in the pre-test, a number of the questions were based on NAPLAN prompts. The use of NAPLAN helps to give the questions authenticity; after all, these questions have recently been used in national tests of Australian children.

The second part of the post-intervention test had six questions of extended answer format. As in Part A, the first five questions required pre-service teachers to describe children's thinking (diagnostic capability) by analysing student working. Pre-service teachers were then asked to describe how they would provide learning support and this related to the specific pedagogy that was recommended and taught in the course. In effect this part of the question assesses Australian Institute for Teaching and School Leadership (AITSL 2014) Standard 3: be able to plan for and implement effective teaching. The sample question in Figure 5 illustrates this format.

Q3: Examine the student script below.

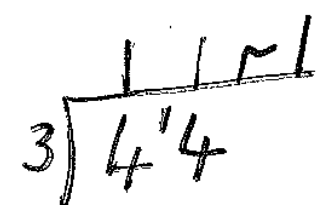

(a) Describe the student error in thinking and subsequent computation. (1 mark) [Space]

(b) Use appropriate materials, and specific language to show how you would build understanding of the division algorithm, using the same 44 divided by 3. ( 4 marks)

\begin{tabular}{lll}
\hline Materials & Language & Symbolism \\
\hline$[$ Space $]$ & {$[$ Space $]$} & [Space]
\end{tabular}

Figure 5. Sample of test of diagnosis (a) and planning for effective teaching (b).

\begin{tabular}{l|l}
1 & Journal of Mathematics Teacher Education. Springer \\
0 &
\end{tabular} 
The coding or marking of the diagnosis was identical to that described above for diagnosis of student thinking. The author marked all questions. The code or mark allocation for Part (b), the description on how to teach particular concepts, was according to the criteria described in Table 1:

Table 1. Descriptors Used to Guide Allocation of Marks for MPCK Part B Questions

\begin{tabular}{|l|l|}
\hline A & $\begin{array}{l}\text { The problem is fully solved and teaching excellent. The response shows evidence of interpretation, } \\
\text { analysis, identification of assumptions, use of appropriate strategies and procedures while showing } \\
\text { initiative. All choices and explanations are justified either with correct language or appropriate symbols } \\
\text { and all steps well explained. Teaching has been explicit with appropriate use of various representations. } \\
\text { (full marks-4 marks) }\end{array}$ \\
\hline B & $\begin{array}{l}\text { The problem is fully solved and teaching very good. The response shows evidence of interpretation, } \\
\text { analysis, identification of assumptions, use of appropriate strategies and procedures while showing } \\
\text { initiative. There may be minor errors in choices and explanations or justification of steps contains minor } \\
\text { omissions. Teaching has been explicit with only minor omissions in the use of appropriate use of various } \\
\text { representations. (close to 75\% of allocated marks- 3.5 to 3 marks) }\end{array}$ \\
\hline C & $\begin{array}{l}\text { The problem has been solved but teaching sequence contains flaws or omissions. While there is } \\
\text { evidence of use of some appropriate strategies; justification, explanations or use of representations have } \\
\text { not been appropriate in significant ways or choices and explanations have not been well explained. A } \\
\text { peer would likely have difficulty following the teaching steps. (close to 50\% of allocated marks- 2.0 to } \\
\text { 2.5 marks) }\end{array}$ \\
\hline D & $\begin{array}{l}\text { The problem has not been solved and teaching sequence is not appropriate. There are significant flaws in } \\
\text { methodology and/or communication is poor or there is a lack of use of appropriate use of representations } \\
\text { and/or linkages between them. (close to 25\% of allocated marks- 1 to 1.5 marks) }\end{array}$ \\
\hline E & $\begin{array}{l}\text { The problem has not been solved. The solution contains significant mathematical errors and the teaching } \\
\text { is likely to lead to student misconception. (close to no marks- 0 to .5 marks) }\end{array}$ \\
\hline
\end{tabular}

For the allocation of full marks for the division-based question above, the author was looking to see if the following specific pedagogical principles were adhered to:

1. The use of bundle sticks on a place-value chart correctly depicting four stages that would illustrate how the bundle sticks would be used to show the division including renaming (regrouping) process. The appropriate and sequential use of materials and models in the teaching of mathematics is widely recommended in teacher education texts (e.g., Booker et al. 2010; Sonnabend 1993; Van de Walle 2007).

2. The use of appropriate place-value language throughout. For example, "Can four tens be shared among three?" "Yes," "Do it! How many tens remain to be shared?" .... Four steps with the symbols that reflect the steps illustrated with the materials. Lack of clarity in the use of language, for example "How many times does 3 go into 4?" warranted the deduction of two marks because 4 tens are to be shared or divided between 3 , and 3 is not going anywhere. Similar lack of clarity in place-value language included, "What is 4 divided by 3?" which warranted the deduction of one or two marks. This is because 4 tens are to be divided, not 4 . Two full marks would be deducted if the pre-service teacher wrote "What is 3 divided by 4?" The omission of the subtraction sign warranted a one-mark deduction. This focus on language is consistent with the recommendations of several authors (e.g., Booker at al. 2010; Hattie 2009) that teacher clarity is one of the most important aspects of effective teaching. Clarity included organisation and explanation, and clarity in the use of consistent and meaningful language.

\begin{tabular}{l|l}
1 & Journal of Mathematics Teacher Education. Springer \\
1 &
\end{tabular} 
Table 2 illustrates the aspects of MCK and PCK that were assessed via particular parts of each test.

Table 2. Questions Assessing MCK and MPCK Pre-test and Post-test in Concept/Content Areas

\begin{tabular}{|c|c|c|c|c|}
\hline Concept area & $\begin{array}{l}\text { Pre-test questions } \\
\text { (MCK) }\end{array}$ & $\begin{array}{l}\text { Post-test Part A } \\
\text { (ii) }(\mathrm{MCK})\end{array}$ & $\begin{array}{lr}\text { Post-test } & \text { Part } \\
\text { A } & \text { (i) } \\
(\mathrm{MPCK}) & \\
\end{array}$ & $\begin{array}{l}\text { Post-test Part B } \\
\text { (i and ii) } \\
(\mathrm{MPCK})\end{array}$ \\
\hline $\begin{array}{l}\text { Whole-number computation and } \\
\text { problem solving }\end{array}$ & $1,2,3,9$ & 1,2 , & 1,2 , & $1,2,3$ \\
\hline $\begin{array}{l}\text { Whole-number skills; classifying } \\
\text { numbers; index HCF, LCM }\end{array}$ & $4,6,7,8$ & $4,5,6$ & $4,5,6$ & \\
\hline $\begin{array}{l}\text { Decimal and fraction numeration } \\
\text { and computation }\end{array}$ & $\begin{array}{l}5 \text { (a \& b) 17, 18, } \\
19,20,21\end{array}$ & $\begin{array}{l}3,9,10,11,12, \\
13,17,20,21 \\
22\end{array}$ & $\begin{array}{l}3,9,10,11, \\
12,13,17, \\
20,21,22\end{array}$ & 4, \\
\hline $\begin{array}{l}\text { Proportional reasoning, problem } \\
\text { computation and problem solving }\end{array}$ & 10, 25, & $7,19,25$ & $7,19,25$ & \\
\hline Algebraic thinking & $22,23,24$, & 15, 18, & 15,18 , & 5, \\
\hline Formal algebra processes & 11, 12 (a \& b), 26 & & & 6 , \\
\hline Measurement and geometry & $13,14,15$ & 23, 24, & & \\
\hline Probability & $16(a, b, c)$ & $8,14,16$ & & \\
\hline
\end{tabular}

For the post-test Part A, the part (i) is essentially diagnosis which is an aspect of MPCK. Part (ii) is pure MCK. For the extended answer section (Part B) of the post-test, part (i) is diagnosis of student thinking and part (ii) assesses MPCK by asking students to explain teaching sequences.

\subsection{Analysis}

A paired t test was used to compare the change in basic content on 11 common questions on the starting and finishing MCK. Simple linear regression analysis enables the relationship between starting MCK and finishing basic content (MCK) to be established. Using both the common 11 questions and the full extended tests of MCK gives an indication of the predictive nature of starting MCK. Descriptive statistics are used to describe student achievement on tests of MCK. A standard simple linear regression was performed to assess the ability of starting MCK to predict finishing MCK and finishing MPCK. The statistical outcomes are informed by the qualitative analysis of the trainee teachers' responses to various test items.

\section{Results}

The starting survey data indicated that all of the pre-service teachers had passed Mathematics 1 and 2 with over $60 \%$ being awarded credit grade or better. The relevance of these data will be reflected upon in the discussion.

\subsection{Research question 1:}

What was the starting MCK of third-year trainee primary teachers and how was this related to their finishing MCK? The results are summarised in Tables 3 and 4.

Table 3. Pre- and Post-test Success on Whole-number Computation and Whole-number Problem solving with Structurally Similar Questions

\begin{tabular}{lcc}
\hline Aspect of test & $\begin{array}{l}\text { Pre } \\
\text { Success }\end{array}$ & $\begin{array}{l}\text { Post } \\
\text { Success }\end{array}$ \\
\hline Whole-number computation and problem solving & & \\
\hline Q2. Luke earned \$257 for each sale he made. If he succeeded in selling 48 items, & $45 \%$ & $83 \%$ \\
what was his total earning? (Post-test equivalent computation) & & \\
Q3. A syndicate of 27 girls shared \$455 between them. How much was each share & $11 \%$ & $54 \%$ \\
to the nearest cent? (Post-test equivalent computation) & &
\end{tabular}

\begin{tabular}{l|l}
1 & Journal of Mathematics Teacher Education. Springer \\
2 &
\end{tabular}


Q6. What is the value of $4^{4}$ ? (Post-test equivalent computation) ; David

gets___ (Post-test equivalent computation)

Q22. Chickens have two legs and goats have four legs. At the farm there are 56

legs and 18 animals and no amputees. How many chickens and how many goats could there be? (Post-test equivalent computation)

The most challenging whole-number computation in the pre-test was division by a double-digit divisor. In this regard the semester 2 cohort were very similar to the semester 1 cohort whose results have been reported elsewhere (Author 2016). Clearly, most students had never been taught to carry out this form of computation, or if they had, they had forgotten how to do so; after the intervention about half the sample could carry out this division computation. In the case of question 6 , the dominant error was that the students did not understand that they needed to multiply 4 by itself 4 times $(4 \times 4 \times 4 \times 4=128)$, indicating a numeracy deficit rather than a computational limitation.

Table 4. Pre- and Post-test Success Rates for Fraction Computation and Problem Solving on Structurally Similar Questions

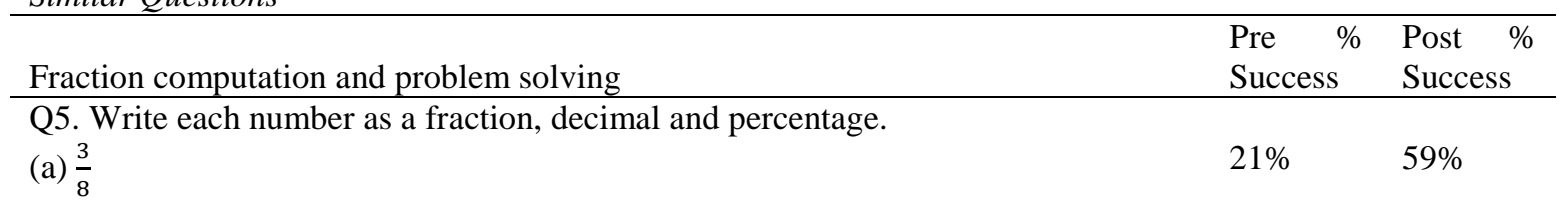

Q18. The arrow is half way between the two fractions. What is the value of the fraction indicated by the arrow? (NAPLAN stimulus)

$19 \% \quad 50 \%$

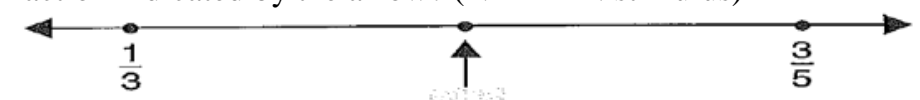

Q19. The small silicon chip has a length $0.2 \mathrm{~mm}$ and a width $0.4 \mathrm{~mm}$. What is the area of the chip?

Q20. A book is $2.5 \mathrm{~cm}$ thick. Each page is $0.05 \mathrm{~mm}$ thick. How many pages are there in the book? (NAPLAN stimulus)

Q17) There were some cars parked in the car yard. $\frac{1}{3}$ of the cars are white and $\frac{1}{4}$ are $\quad 8 \% \quad 81 \%$ red. There were nine more white cars than red cars. How many cars were there altogether?

The pre-test data indicate that pre-service teachers entered the third-year course with average levels of wholenumber and fraction competency that was low by almost any measure. The content in the sample questions above is consistent with minimum standards for Year 6 and 7 of ACARA (2012).

The pre-test and post-test data were used to explore the relationship between them and to help reflect upon the effect of the intervention. In order to quantify the significance of any change in MCK only 11 common items and the full tests were used. The use of the 11 common items enabled the use of paired t-tests. It should be noted that the correlation coefficient between the short test and the entire pre-test two tests was .846 and the average percentage scores were virtually identical on each test at $29 \%$ for the common 11 items only and $30 \%$ for the extended test that contained 34 items. The use of the extended test data adds relevant educational context. Purely on the basis of the common 11 questions in pre- and post-MCK, and paired t test, the post-intervention scores ( $M=5.26$, [58\% success] standard error mean 0.17) were greater than the pre-intervention scores $(M=2.62$, [29\% success] standard error mean 0.156). This difference, -2.647, BCa 95\% CI [-2.95, -2.32] was significant $\mathrm{t}(149)-16.602, \mathrm{p}=0.000$. While this is statistically significant the educational significance is a more complicated question.

\begin{tabular}{l|l}
1 & Journal of Mathematics Teacher Education. Springer \\
3 &
\end{tabular} 
The relationship between abbreviated pre-test MCK common questions and post-test MCK common questions was assessed using a simple linear regression which calculated to predict post-test MCK. A significant regression equation was found $(\mathrm{F}(1,148)=57.241, \mathrm{p}<000)$, with $R^{2}$ of .279 . Participants' predicted post-test MCK is equal to $7.494+1.153$ pre-test MCK with the scores valued in marks. Participants' post-test MCK increased 1.153 for each mark of the pre-test MCK.

The use of the fuller tests (36 marks on pre-test; 25 marks on post-test) of both pre- and post-MCK accounted for a greater proportion of the variance as indicated by the greater $R^{2}$. The simple linear regression calculated to predict post-test MCK based on pre-test MCK (full tests) found a significant regression equation $(\mathrm{F}(1,148)=$ 117.674, $\mathrm{p}<.000$ ), with $R^{2}=.649$. Participants' predicted post-test full-test MCK is equal to $9.973+.601$ (pretest MCK) when post-test MCK is measured in marks. Participants' post-test MCK increased by .601 marks for each mark of the independent variable. These comparisons mean that student gains were stronger on the limited concepts that were the focus of the common questions, but the extended test of MCK showed greater accounting for variance in post-test scores of MCK. For this reason the extended pre-test of MCK and extended post-test MCK were used to assess the relationship between MCK and MPCK. 


\subsection{Research Question 2}

\section{How was starting MCK related to MPCK?}

The paired t test on this aspect of MCK and the post-test MPCK (diagnosis) (M=19.26 [77\% success] and standard error mean .358) were greater than MCK (M=16.18 [65\% success] and standard error mean .392). This difference - 3.078, BCA 95\% CI [-3.43, -2.73] was significant t (151) -17.446, p=000. That is, pre-service teachers were better at finding and describing errors than in providing the correct solution themselves.

The relationship on post-test MCK and description of children's thinking (diagnosis), an aspect of MPCK associated with the 25 questions (see Figure 1) summarised in Table 5, was assessed via simple linear regression which was calculated to predict the diagnostic capacity from pre-service teachers' MCK associated with each of the 25 questions. A significant regression equation was found $(\mathrm{F}(1,150)=582.851, \mathrm{p}<000)$, with $R^{2}$ of 0.795 . Participants' predicted diagnostic score was equal to 5.986+.820 (MCK) when diagnostic score was measured in marks. The diagnostic capacity increased by .820 marks for each mark of MCK. The strong $R^{2}$ value suggests about $80 \%$ of the variance in diagnostic capability is accounted for in the model.

The summary of Part A (diagnosis [a] and MCK [b]) is shown in Table 5.

Table 5. Mean Scores /1 for Diagnosis and Correct Solution /1. Part A of Post-test

\begin{tabular}{|c|c|c|c|}
\hline Q & Concept & $\begin{array}{l}\text { Part A } \\
\text { diagnosis }\end{array}$ & $\begin{array}{l}\text { Part B } \\
(\mathrm{MCK})\end{array}$ \\
\hline 1 & Assessment and knowledge of multiplication & .97 & .83 \\
\hline 2 & Assessment and knowledge of division & .85 & .54 \\
\hline 3 & Assessment and knowledge of division (Figure 1) & .71 & .59 \\
\hline 4 & Assessment and knowledge of index convention & .93 & .79 \\
\hline 5 & Assessment and knowledge of LCM & .56 & .41 \\
\hline 6 & Assessment and knowledge of simple problem solving & .86 & .75 \\
\hline 7 & Assessment and knowledge of ratio & .76 & .75 \\
\hline 8 & Assessment and knowledge of probability & .77 & .60 \\
\hline 9 & Assessment and knowledge of mixed numbers computation & .94 & .54 \\
\hline 10 & Assessment and knowledge of fraction computation & .84 & .81 \\
\hline 11 & Assessment and knowledge of fraction remaining & .70 & .50 \\
\hline 12 & Assessment and knowledge of decimals operations & .54 & .55 \\
\hline 13 & Assessment and knowledge of decimal operations & .48 & .10 \\
\hline 14 & Assessment and knowledge of probability computation & .53 & .15 \\
\hline 15 & Assessment and knowledge of problem-solving strategies & .75 & .53 \\
\hline 16 & Assessment and knowledge of simple probability & .85 & .83 \\
\hline 17 & Assessment and knowledge of fraction naming & .95 & .93 \\
\hline 18 & Assessment and knowledge of simple algebraic thinking & .89 & .72 \\
\hline 19 & Assessment and knowledge of proportion & .61 & .51 \\
\hline 20 & Assessment and knowledge of fraction naming & .91 & .92 \\
\hline 21 & Assessment and knowledge of percentage problem solving & .53 & .48 \\
\hline 22 & Assessment and knowledge of fraction problem solving & .85 & .82 \\
\hline 23 & Assessment and knowledge of simple measurement & .99 & .98 \\
\hline 24 & Assessment and knowledge of measurement problem solving & .77 & .75 \\
\hline 25 & Assessment and knowledge of percentage problem solving & .92 & .76 \\
\hline Total & This section represents $25 \%$ of the total assessment(75 Marks) & $77 \%$ & $65 \%$ \\
\hline
\end{tabular}


The detail contained in Table 5 indicates that, consistent with the statistical data, on almost every question PSTs were more successful in identifying a student error than in providing a correct solution. Further, where preservice teachers did not know how to answer the question, they tended to be less able to describe children's error patterns. For example, Question 13 related to decimal operations; the mathematical success rate was $10 \%$ and reasonable interpretation of student error was $48 \%$.

A multiple linear regression was calculated to predict MPCK (6 questions) based on pre-test MCK (extended test) and post-test MCK (extended test). A significant regression equation was found $(\mathrm{F}(2,147)=63.328$. $\mathrm{p}<$ .000 ), with $R^{2}$ of .463 . The trainee teachers' MPCK was equal to $5.717+.862$ (post MCK) +.032 (pre-test MCK), where scores were measured in marks. MPCK increased 0.032 marks for each mark on the pre-test MCK and .862 marks for each mark on the post-test MCK. Both independent variables were significant predictors of MPCK. The adjusted $R^{2}$ of .456 suggests that about $46 \%$ of the total variability of MPCK is explained by the MCK, with post-test MCK having the greater predictive value. It is expected that MCK at the time of testing of MPCK would be more relevant than MCK tested at an earlier time. The brief summary is that students who knew more mathematics were better at explaining what children might have done wrong and what learning support could be offered. The summary of results is shown in Table 7.

Table 6. Summary of MPCK, Part B of Post-test $(n=152)$

\begin{tabular}{|c|c|c|c|c|}
\hline $\begin{array}{l}\text { Question and content } \\
\text { domain }\end{array}$ & Description of task & Mean & $\%$ & SD \\
\hline 1) Whole number & (a) Error diagnosis (1 mark) & 0.960 & $96 \%$ & 0.1953 \\
\hline \multirow[t]{2}{*}{ subtraction } & (b) Create missing part contextual story (1 mark) & 0.579 & $58 \%$ & 0.4886 \\
\hline & (c) Describe specific pedagogy (3 marks) & 2.705 & $45 \%$ & 0.6959 \\
\hline 2) Two by two digit & (a) Error diagnosis (1 mark) & 0.728 & $73 \%$ & 0.4410 \\
\hline multiplication & (b) Describe specific pedagogy (4 marks) & 3.310 & $83 \%$ & 1.2748 \\
\hline 3) Division by a single & (a) Error diagnosis (1 mark) & 0.821 & $82 \%$ & 0.3788 \\
\hline digit divisor & (b) Describe specific pedagogy (4 marks) & 2.307 & $58 \%$ & 1.5246 \\
\hline \multirow[t]{2}{*}{$\begin{array}{l}\text { 4) Fraction and } \\
\text { percentage }\end{array}$} & $\begin{array}{l}\text { (a) Application of fractions and percentage in a problem } \\
\text { context- error diagnosis ( } 1 \text { mark) }\end{array}$ & 0.815 & $82 \%$ & 0.3886 \\
\hline & (b) Describe justifiable pedagogy (4 marks) & 3.211 & $80 \%$ & 1.5011 \\
\hline \multirow[t]{2}{*}{ 5) Early algebra } & (a) Diagnosis of early algebra error (1 mark) & 0.516 & $52 \%$ & 0.4964 \\
\hline & (b) Describe justifiable pedagogy (4 marks) & 1.886 & $47 \%$ & 1.8648 \\
\hline $\begin{array}{l}\text { 6) Algebra problem } \\
\text { solving }\end{array}$ & $\begin{array}{l}\text { (a) Justifiable application of Polya's problem-solving } \\
\text { model to the teaching up algebra problem solving ( } 5 \\
\text { marks) }\end{array}$ & 2.201 & $44 \%$ & 2.0533 \\
\hline Total & (30 marks) & 20.040 & $67 \%$ & 2.0533 \\
\hline
\end{tabular}

As noted of the earlier MPCK data, these data indicate that for each question, students were better at error description, or evaluating children's thinking, than at describing how they might provide learning support. Explaining how they might teach subtraction (45\% average), division (58\%) and any algebra (52\% and 44\%) was challenging. Pre-service teachers who struggled to explain the teaching frequently could not do the mathematics themselves.

\section{Discussion}

It is well recognised that "teacher knowledge, and especially MPCK, is difficult to measure" (Beswick and Goos 2012, p. 74) and as Gess-Newsome (2013, p. 259) explained, "it is important to find alternative measures to understand what teachers know and do". One aspect of this study was to trial various alternative methods, including assessment of pre-service teachers around "tasks of teaching..." (Chapman 2015, p. 119). The methods used, in particular the scoring of analysing student work, is an alternative approach to that taken by

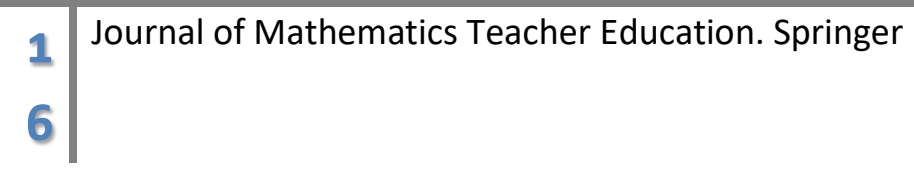


Tatto et al. (2008). In this regard the method builds on the work of earlier authors (e.g., Beswick and Goos 2012; Chapman 2015; Chick et al. 2006; Marshman and Porter 2013).

There are sufficient data to propose a response to the first research question (What was the starting MCK of third-year PSTs and how was this related to their finishing MCK. The average mark on the entire pre-test was $30 \%$ success, while the average mark on the 11 common questions only, which focused on testing wholenumber computation and problem solving and fraction computation and problem solving, was 29\%. The two measures were highly correlated (.845). Considering the novice nature of most of the questions such results would be a cause for concern by most mathematics educational researchers (e.g., Beswisk and Goos 2012; Burghes and Geach,2011; Krainer et al. 2015; Qian and Youngs 2016; Tatto et al. 2008). Recall that in past years, these pre-service teachers would have graduated without the additional intervention described in this study. Comparisons with Burghes and Geach's (2011) data suggest that they are lower than U.K. results on the same questions. The data confirm the concerns raised by the Teacher Education Ministerial Advisory Group (TEMAG 2014) that Australian PSTs education institutions have accepted and graduated students with relatively low levels of personal numeracy. In this regard the study has findings similar to Hine (2015) and Beswick and Goos (2012) for Australia, and Ingram and Linsell (2014) and Major and Perger (2014) for New Zealand. Other authors, including Burghes and Geach (2011), Tatto et al. (2015) and Qian and Youngs (2016), have suggested this is a challenge in other Western nations including England and the US.

The pre- and post-test comparison using a paired t test suggests a significant improvement subsequent to the teaching intervention, approximating a doubling of average grade (29\% mean success to $58 \%$ mean success). Such gains ought to have been anticipated; after all, developing MCK while learning to teach the content (MPCK) was the intent of the course. In this regard the focus of the intervention attempted to account for the advice of Beswick and Goos (2012, p., 82): “although teacher education needs to attend to sophisticated concepts involving abstract thinking, the weak mathematics knowledge of entering pre-service teachers ... means that simple knowledge and skills cannot be taken for granted.” The results presented in this paper document the extent of the challenge, at least in the sample of pre-service teachers studied.

The near doubling of the mean scores on common questions that were a focus of the intervention conforms to the observations of Qian and Youngs (2016) that the effectiveness of a program or course is highly dependent upon the content and learning activities of specific courses. What was particularly useful in the context of this study was the focus on content associated with whole-number computation, fractions, proportional reasoning across the strands, and early algebraic thinking. This is quite a narrow focus compared to the spread examined by Tatto et al. (2008) who included greater detail in number and algebra and a great deal more evaluation of geometry and data.

Unfortunately, the entry data indicate that the early mathematics curriculum courses did little to develop the PSTs' MCK to the level of novice (as described by Beswick and Goos 2012; Tatto et al. 2008). In this regard the data lend evidence to the claims by a range of authors that discipline knowledge (MCK) has been de-emphasised in Western institutions' teacher education programs (e.g., Graven 2002; Hattie 2009; Henderson and Rodrigues 2008; Hine 2015; Kotzee 2012; Meyers 2012; Muller 2000; Stipek et al. 2001). The exact reasoning for this apparent failure to support pre-service teachers' personal MCK growth is a question for additional research, but the data lend support for the hypothesis that knowing the mathematics was not a focus of earlier mathematics curriculum courses. The educational traditionalists (e.g., Bernstein 1999; Muller 2000, 2009; Muller and Taylor 1995; Young 2011) cited above would be joined by cognitive load theorists (Chen et al. 2016; Kirschner et al. 2006; Owen and Sweller 1989) and East Asian educators (e.g., Leung et al. 2015) in suggesting that without explicit MCK, numbers of the pre-service teachers would struggle to scaffold mathematics learning effectively. Others, including Poulson (2001), might argue that these results are not educationally significant, since the author's tests were measures of explicit knowledge and did not tap into the PSTs' tacit knowledge of teaching mathematics. Further, the results ignore the ongoing opportunities for trainee teachers to learn in classrooms and from future wider professional conduct.

\begin{tabular}{l|l}
1 & Journal of Mathematics Teacher Education. Springer \\
7 &
\end{tabular} 
In regard to the success or otherwise of the intervention, it needs to be noted that with regard to fraction computation and problem solving, about half the PSTsretained significant challenges by the end of the course, not to mention the much broader suite of knowledge domains considered essential by other researchers (e.g., Tatto et al. 2008) and demanded by mathematics curriculum documents (e.g, ACARA 2017b; NCTM 2015). From an educational perspective, those authors who favour a deep and connected or profound knowledge of the content would be concerned (e.g., Ball et al. 2008; Hattie 2009; Ma 1999; Masters 2009; Tatto et al. 2015; TEMAG 2014).

The relatively low $R^{2}$ value (.278) for pre- and post-test on the 11 common questions suggests that some students who performed poorly on the pre-test MCK were able to remediate this situation. Recall that the longer tests had a greater capacity to account for variance $\left(R^{2}\right.$ value .649$)$. These data indicate that the MCK with which students came to the course was a relatively good predictor of how they would fare on the final test of MCK, in that if students knew more mathematics at the start, they tended to succeed more on final tests of MCK. The predictive capacity of starting MCK on ending MCK suggests that in teaching for procedural understanding and mathematical fluency or content knowledge for teaching (Ball et al. 2008; Hine 2015), prior engagement with mathematics curriculum courses has some merit and warrants further research. This option is discussed later; the question posed is whether this is the most effective way to develop MCK.

The second research question focused on examining the relationship between MCK and MPCK. Multiple linear regression statistics indicated that both pre-test and post-test MCK were positively predictive of measured MPCK. However, post-test MCK $\left(R^{2} .456\right)$ was a better predictor of MPCK that starting MCK. It makes sense that those pre-service teachers who were stronger at articulating their mathematics knowledge at the end of the course would achieve more highly on measures of MPCK. If the PSTs could not do whole-number division themselves, they gained few marks for explaining how they might scaffold the learning of division. On the other hand, where pre-service teachers could do the mathematics, such as two-digit by two-digit multiplication, they tended to score more highly in describing the pedagogy. This finding highlights the critical role of mathematical fluency and understanding for the planning of pedagogy.

A further finding was the high $R^{2}$ value of .791 ; that is, about $80 \%$ of the variance in pre-service teachers' capacity to identify and describe student errors was accounted for by their MCK of specific mathematics. These data are novel and diminish the arguments put forward that generic capability can be transferred across concepts and mathematical levels. In other words, capability to diagnose errors or student thinking in the context of decimal division errors is highly correlated to the pre-service teacher's MCK of the decimal division process. Fluency in an alternative content domain such as addition of decimals may well be irrelevant to success in decimal division diagnosis. This finding is an extension of the thinking of Hattie and Donoghue (2016) that deep learning is context specific and when the context changes, old strategies may no longer work. The implications of this are that if PST are to be graduated as classroom ready in the sense of having deep knowledge of the pedagogy of an extensive list of concepts, significant investment of time is needed.

\section{Conclusions and implications}

The data on MCK on the pre-test indicate that many of the PSTs were able to enrol in teacher education with limited MCK, and several university curriculum courses (including this intervention) did not appear to address this challenge to the degree that might be hoped for. The detail of novice-like errors in basic whole number computation and the extent of difficulty experienced with fractions, proportion and any problem solving adds a new dimension that confirms the previously reported concerns with respect to MCK of pre-service and inservice primary teachers in the West (e.g., Burghes and Geach 2011; Hine 2015; Ingram and Linsell 2014; Krainer et al. 2015; Major and Perger 2014; Tatto et al. 2015).

The relatively weak account for variation of starting MCK compared to later MCK weakens the argument for content-specific courses prior to commencement of learning to teach mathematics, particularly if other options have not been fully explored. One option is to teach the content while developing the specific pedagogy to teach 
it, that is, to integrate the development of MCK and MPCK such as modelled in the intervention described. The increase in predictive power of MCK for MPCK with increased alignment of specific content with MPCK supports the recommendation of researchers including Delaney et al. (2008) and Hine (2015) who use the term mathematical content for teaching, and conforms to the recommendations of authors (e.g., Beswick and Goos 2012; Gess-Newsome 2013 and others) that pre-service programs need to account for the weak mathematics knowledge of substantial portions of PSTs. In addition, the relatively strong predictive potential of MCK for MPCK may cast doubt on the arguments summed up by Poulson (2001) that formal knowledge of mathematics may not be particularly relevant to successful primary mathematics teaching and supports the many authors who consider a threshold level of MCK essential. While it may be possible to rely on tacit knowledge to teach counting to early childhood students, it would seem problematic to rely on these knowledge forms to teach concepts such as division or fractions. This would certainly be the conclusion supported by East Asian educators (Leung et al. 2015), the majority of Western theorists and educational bodies including U.S. Department of Education (2008), the Australian Academy of Science (2015), AITSL (2014), and increasingly, researchers in teacher preparation such as those cited above. In 2016 Hattie and Donoghue discussed the relationship between surface and deep learning. In a manner, MCK can be considered the required surface learning necessary for the deeper application of this knowledge in MPCK.

The levels of graduates' MCK and MPCK suggest that current program practices with respect to time, focus and teaching warrant review. Among the options that could be explored are increasing the priority on MCK and MPCK within current time frames and program structures and/or changing program structures such that there is more time and opportunity to develop pre-service teachers' knowledge of mathematics and how to teach it. Such restructuring might include mandatory primary teacher specialisation, particularly for upper primary school. Further considerations include greatly increasing the learning opportunities for pre-service teachers.

The novelty in this paper includes a rich description of attempts to increase MCK and MPCK subject to the constraints of a short duration mathematical curriculum course in which many of the PSTs had very significant deficits in their depth of mathematical understanding. Further, the paper increases our understanding of the complex relationship between MCK and MPCK and introduces methods to quantify each.

\section{Limitations}

Most educational research in teaching settings is problematic since numerous variables cannot be controlled or effectively measured. In this study there are clear methodological challenges and limitations. The pre-test is derived from content tests such as those used by Burghes (2008) and MCEETYA (2014-2015) so we can be reasonably confident of their validity and reliability. The use of only 10 questions from the pre-test in the posttest weakens the statistical power of the paired $t$ test, but it is unlikely that this is educationally significant since the detail of the longer tests provides considerable insight. The validity and reliability of the tests of MPCK are an unknown factor. In regard to the analysis it is recognised that the use of Ordinary Least Squares models in analysing repeated measures data has increased the probability of type 1 error occurrence. However, this limitation is mitigated somewhat when the data are balanced (participants' time series data are collected at the same intervals) as was the case in this study. It is up to the reader to decide if the data and subsequent inferences are transferable to their situations.

\section{References}

Adler, J., \& Davis, J. (2006). Opening another black box: Researching mathematics for teaching in mathematics teacher education. Journal for Research in Mathematics Education, 37(40), 270296.

Australian Academy of Science. (2015). Desktop review of mathematics education pedagogical approaches and learning resources. http://www.science.org.au/ Accessed 15 May 2015.

\footnotetext{
1 Journal of Mathematics Teacher Education. Springer 
Australian Association of Mathematics Teachers AAMT (1996). Statement on the Use of Calculators and Computers for Mathematics in Australian Schools, 1996. AAMT Inc. Adelaide.

Australian Curriculum, Assessment and Reporting Authority (ACARA). (2012).The Australian Curriculum: Mathematics. http://www.australiancurriculum.edu.au/Mathematics/Rationale/ Accessed 28 May 2013. Australian Curriculum, Assessment and Reporting Authority (ACARA). (2014a). Numeracy non-calculator Year 7. National Assessment Program Litercy and Numeracy.

Australian Curriculum, Assessment and Reporting Authority (ACARA). (2014b). Numeracy Year 5. National Assessment Program Litercy and Numeracy.

Australian Curriculum, Assessment and Reporting Authority (ACARA). (2017a). Australian Curriculum: Mathematics. http://v7-5.australiancurriculum.edu.au/mathematics/curriculum/f-10?layout=2\#page=1. Accessed 30 May 2017.

Australian Curriculum, Assessment and Reporting Authority (ACARA). (2017b). Numeracy across the Australian Curriculum. http://v7.australiancurriculum.edu.au/generalcapabilities/numeracy/introduction/numeracy-across-thecurriculum. Accessed 25 Sept 2017.

Australian Institute for Teaching and School Leadership. (AITSL). (2014). Australian Professional Standards for Teachers. http://www.aitsl.edu.au/australian-professional-standards-for-teachers/standards/list/ Accessed 02 February 2015.

Author (2012; 2014; 2016) [details removed for peer review]

Ball, D., \& Bass, H. (2000). Interweaving content and pedagogy in teaching and learning to teach: Knowing and using mathematics. In J. Boaler (Ed.), Multiple perspectives on the teaching and learning of mathematics (pp. 83-104). Westport, CT: Ablex.

Ball, D., Thames, M., \& Phelps, G. (2008). Content knowledge for teaching: What makes it special? Journal of Teacher Education, 59, 389-407.

Bernstein, B. (1999). Vertical and horizontal discourse: An essay. British Journal of Sociology of Education, 20(2), 157-173.

Bernstein, B. (2000). Pedagogy, Symbolic control and identity (Rev. ed.). Lanham, Boulder, New York, Oxford: Rowan \& Littlefield Publishers, Inc.

Beswisk, K., \& Goos, M. (2012). Measuring pre-service teachers’ knowledge for teaching mathematics. Mathematics Teacher Education and Development, 14(2), 70-90.

Bobis, J., Mulligan, J., \& Lowrie, T. (2004). Mathematics for children: Challenging children to think mathematically. Frenchs Forest: Pearson.

Booker, G., Bond, D., Sparrow, L., \& Swan, P. (2010). Teaching primary Mathematics. Frenchs Forest: Pearson Hall.

Brown, G., \& Quinn, R. J. (2006). Algebra students’ difficult with fractions: An error analysis. Australian Mathematics Teacher, 62(4), 28-40.

Brown, G., \& Quinn, R. J. (2007). Fraction proficiency and success in algebra. Australian Mathematics Teacher, 63(3), 23-29. 
Burghes, D. (2008). International comparative study in Mathematics training. Trainee Teacher Primary Mathematics Audit. (ICSMTT) CfBT Education Trust. http://www.cimt.plymouth.ac.uk/papers/icsmtt.pdf / Accessed 02 February 2015.

Burghes, D.\& Geach, R. (2011). International comparative study in Mathematics training: Recommendations for initial teacher training in England. CfBT Education Trust.

https://www.nationalstemcentre.org.uk/res/documents/page/International\%20comparative\%20study\%2 0in\%20mathematics\%20teacher\%20training.pdf/ Accessed 07 March 2013.

Callingham, R., Beswick, K., Clark, J., Kissane, B., Serow, P., \& Thorton, S. (2012). Mathematical knowledge for teaching of MERGA Members. In J. Dindyal, L. P. Chen \& S. F. Ng (Eds.), Mathematics education: Expanding horizons (Proceedings of the $35^{\text {th }}$ annual conference of the Mathematics Education Research Group of Australasia). Singapore: MERGA.

Chapman, O. (2015). Understanding and supporting teachers’ knowledge for teaching. Journal of Mathematics Teacher Education, 18, 101-103.

Chen, O., Kalyuga, S., \& Sweller, J. (2016). Relations between the worked example and generation effects on immediate and delayed tests. Learning and Instruction, 45, 20-30.

Chick, H., Pham, T., \& Baker, M. (2006). Probing teachers’ pedagogical content knowledge: Lessons from the case of the subtraction algorithm. In P. Grootenboer, R. Zevenberg \& M. Chinnapan (Eds.), Identities, cultures and learning spaces: Proceedings of the $29^{\text {th }}$ annual conference of the Mathematics Education Research Group of Australasia (pp. 139-146). Adelaide: MERGA.

Delaney, S., Ball, D., Hill, H., Schilling, S., \& Zopf, D. (2008). Mathematical content knowledge for teaching: Adapting U.S. measures for use in Ireland. Journal of Mathematics Teacher Education, 11(3), 171-197.

Dohrmann, M., Kaiser, G., \& Blomeke, S. (2012). The conceptualisation of mathematics competencies in the international teacher education study TEDS-M. Mathematics Education, 44, 325-340.

Gess-Newsome, J. (2013). Pedagogical content knowledge. In J. Hattie \& E. Anderman (Eds.), International guide to student achievement (pp. 257-259). New York: Routledge.

Goldsmith, L., Doerr, H., \& Lewis, C. (2014). Mathematics teachers’ learning: A conceptual framework and synthesis of research. Journal of Mathematics Teacher Education, 17, 5-36.

Graven, M. (2002). Mathematics teacher learning, communities of practice and the centrality of confidence. Thesis submitted to the Faculty of Science, University of the Witwatersrand, Johannesburg.

Hattie, J. (2009). Visible learning: A synthesis of over 800 meta-analyses relating to achievement. London: Routledge.

Hattie, J., \& Donoghue, G. (2016). Learning strategies: A synthesis and conceptual model. npj Science of Learning, 1. http://www.nature.com/npjcilearn Accessed 25 May 2017.

Henderson, S., \& Rodrigues, S. (2008). Scottish student primary teachers' levels of mathematical competence and confidence for teaching mathematics: Some implications for national qualifications and initial teacher education. Journal of Education for Teaching, 34(2), 93-107.

Hill, H., Rowan, B., \& Ball, D. (2005). Effects of teachers' mathematical knowledge for teaching on student achievement. American Educational Research Journal, 42(2), 371-406.

\footnotetext{
2 Journal of Mathematics Teacher Education. Springer 
Hine, G. (2015). Strengthening pre-service teachers' mathematical content knowledge. Journal of University Teaching \& Learning 12(4), 1-13.

Ingram, N., \& Linsell, C. (2014). Foundation content knowledge: Pre-service teachers’ attainment and affect. In J. Anderson, M. Cavanagh, \& A. Prescott (Eds.), Curriculum in focus: Research guided practice. Proceedings of the $37^{\text {th }}$ annual conference of the Mathematics Education Research Group of Australasia (pp. 718-712). Sydney: MERGA.

Jacobson, E., \& Kilpatrick, J. (2015). Understanding teacher affect, knowledge, and instruction over time: An agenda for search on productive disposition for teaching mathematics. Journal of Mathematics Teacher Education, 18, 401-406.

Kirschner, P., Sweller, J., \& Clark, R. (2006). Why minimal guidance during instruction does not work: An analysis of the failure of constructivist, discovery, problem-based, experiential, and inquiry-based teaching. Educational Psychologist, 41(2), 75-86.

Klein, D. (2005). The state of state Math standards. Thomas B. Fordham Foundation.

Kotzee, B. (2012). Expertise, fluency and social realism about professional knowledge. Journal of Education and Work, 27(2), 161-178. http://www.tandfonline.com/doi/abs/10.1080/13639080.2012.738291 Accessed 02 Feb, 2015.

Krainer, K., Hsieh, F-J., Peck, R., \& Tatto, M. (2015). The TEDS-M: Important issues, results and questions. In S. J. Cho (Ed.), Proceedings of the $12^{\text {th }}$ International Congress on Mathematical Education. Intellectual and attitudinal challenges (pp. 99-122). Springer, Open.

Leung, F., Park, K., Shimizu, Y., \& Xu, B. (2015). Mathematics education in East Asia. The TEDS-M: Important issues, results and questions. In S. J. Cho (Ed.), Proceedings of the $12^{\text {th }}$ International Congress on Mathematical Education. Intellectual and attitudinal challenges (pp. 123-143). Springer, Open.

Livy, S., \& Herbert, S. (2013). Pre-service teachers’ responses for ratio and proportion items. In V. Steinle, L. Ball, \& C. Bardini (Eds.), Mathematics education: Yesterday, today and tomorrow: Proceedings of the $36^{\text {th }}$ annual conference of the Mathematics Education Research Group of Australasia (pp. 450-457). Melbourne, VIC: MERGA.

Ma, L. (1999). Knowing and teaching elementary mathematics: Teachers' understanding of fundamental mathematics in China and the United States. Mahwah, NJ: Lawrence Erlbaum Associates, Inc.

Major, K., \& Perger, P. (2014). Personal number sense and New Zealand pre-service teachers. In J. Anderson, M. Cavanagh, \& A. Prescott (Eds.), Proceedings of the $37^{\text {th }}$ annual conference of the Mathematics Education Research Group of Australasia (pp. 710-713). Sydney: MERGA.

Marshman, M., \& Porter, G. (2013). Pre-service teachers’ pedagogical content knowledge: Implications for teaching. In V. Steinle, L. Ball, \& C. Bardini (Eds.), Mathematics education: Yesterday, today and tomorrow. Proceedings of the $36^{\text {th }}$ annual conference of the Mathematics Education Research Group of Australasia (pp. 474-481). Melbourne, VIC: MERGA.

Mason, J. (2016). Rising above a cause-and-effect stance in mathematics education research. Journal of Mathematics Teacher Education, 19, 297-300. 
Masters, G. (2009). A shared challenge: Improving literacy, numeracy and science learning in Queensland primary schools. Australian Council for Educational Research. http://education.qld.gov.au/mastersreview/ Accessed 31 January 2011.

Meyers, D. (2012). Australian universities: A portrait of decline. http://www.australian universities.id.au/ Accessed 09 May 2014.

Ministerial Council on Education, Employment, Training and Youth Affairs (MCEETYA). (2014-2015). National assessment program, literacy and numeracy: Numeracy. Carlton, Victoria: Curriculum Corporation.

Muller, J. (2000). Reclaiming knowledge: Social theory, curriculum and education policy. London and New York: Routledge Falmer.

Muller, J. (2009). Forms of knowledge and curriculum coherence. Journal of Education and Work, 22(3), 205226. http://www.tandfonline.com/loi/cjew20 Accessed 24November 2012.

Muller, J., \& Taylor, N. (1995). Schooling and everyday life: Knowledges sacred and profane. Social Epistemology: A Journal of Knowledge, Culture and Policy, 9(3), 257-275. Retrieved from http://dx.doi.org/10.1080/02691729508578791

Mullis, I., Martin, M., Foy, P., \& Arora, A. (2012). TIMMS International Results in Mathematics. http://timssandpirls.bc.edu/timss2011/international-results-mathematics.html/ Accessed 09 May 2014.

National Council of Teachers of Mathematics. (2014). Executive summary: Focus in high school mathematics: Reasoning and sense making. http://www.nctm.org/standards/content.aspx?id=23749/ Accessed 25 March 2015.

National Council of Teachers of Mathematics. (2015). Principles and standards of school mathematics. http://www.nctm.org/Standards-and-Positions/Principles-and-Standards/Principles,-Standards,-andExpectations/ Accessed 14 January 2016.

Norton, S. (2012). The use of alternative algorithms in whole number computation. International Journal of Mathematics Teaching and Learning. (October 26: 2012; p. 2-16) Available from; http://www.cimt.plymouth.ac.uk/journal/default.htm

Norton, S. (2014). Teaching and Learning Fundamental Mathematics. Retrieved from: https://mathematicseducation.vhx.tv/products/teaching-and-learning-fundamental-mathematics

Norton, S. \& Zhang, Q. (2016). Primary mathematics teacher education in Australia and China: What might we learn from each other? Journal of Mathematics Teacher Education. Available online from: http://link.springer.com/article/10.1007/s10857-016-9359-6

Organization for Economic Co-operation and Development (OECD). (2014). Education at a glance, 2014. http://www.oecd.org/edu/Education-at-a-Glance-2014.pdf/ Accessed 10 December 2015.

Owen, E., \& Sweller, J. (1989). Should problem solving be used as a learning device in mathematics? Journal for Research in Mathematics Education, 20(3), 322-328.

Poulson, L. (2001). Paradigm lost? Subject knowledge, primary teachers and education policy. British Journal of Educational Studies, 49(1), 40-55.

Reisman, F. (1978). A guide to the diagnostic teaching of arithmetic. Columbus, OH: Charles E. Merrill Publishing Company. 
Qian, H., \& Youngs, P. (2016). The effect of teacher education programs on future elementary mathematics teacher's knowledge: A five country analysis using TEDS-M data. Journal of Mathematics Teacher Education, 19, 371-396.

School of Education and Professional Studies. (2017). A rewarding teacher career starts here. https://www.griffith.edu.au/education/school-education-professional-studies Accessed 07 March 2017.

Shulman, L. (1987). Knowledge and teaching: Foundations of the new reform. Harvard Educational Review, 57(1), 1-22.

Sonnabend, T. (1993). Mathematics for elementary teachers: An interactive approach. New York: Saunders College Publishing.

Stipek, D., Givvin, K., Salmon, J., \& MacGyvers, V. (2001). Teachers’ beliefs and practices related to mathematics instruction. Teacher and Teaching Education, 17, 213-226.

Sweller, J. (2016). Working memory, long-term memory, and instructional design. Journal of Applied Research in Memory and Cognition, 5, 360-367.

Tatto, M., Rodriguez, M., \& Lu, Y. (2015). The influence of teacher education on mathematics teaching knowledge: Local implementation of global ideas. International Perspectives on Education and Society, 27, 279-331. http://www.emeraldinsight.com/doi/pdfplus/10.1108/S1479367920140000027004/ Accessed 12 December 2015.

Tatto, M., Schwille, J., Senk, S., Ingvarason, L., Peck, R., \& Rowley, G. (2008). Teacher education and development study in Mathematics (TEDS-M): Policy, practice, and readiness to teach primary and secondary mathematics. Conceptual framework. East Lansing, MI: Teacher Education and Development International Study Center, College of Education, Michigan University.

Teacher Education Ministerial Advisory Group, (2014). Action now! Classroom ready teachers. http://docs.education.gov.au/system/files/doc/other/action_now_classroom_ready_teachers_print.pdf/ Accessed 10 December 2014.

The World University Rankings, (2017). Graduate employability: Top universities in Australia ranked by employers. https://www.timeshighereducation.com/student/best-universities/graduate-employabilitytop-universities-australia-ranked-employers Accesssed 09 May 2017.

U.S. Department of Education. (2008). Success: The final report of the National Mathematics Advisory Panel. http://www2.ed.gov/about/bdscomm/list/mathpanel/report/final-report.pdf/ Accessed 04.02.14.

Van de Walle, J. (2007). Elementary and middle school Mathematics: Teaching developmentally. Boston; Pearson.

Wilson P., Cooney, T., \& Stinson, D. (2005). What constitutes good mathematics teaching and how it develops: Nine high school teachers’ perspectives. Journal of Mathematics Teacher Education, 8(2), 83-111.

Young, M. (2011). The return to subjects: A sociological perspective on the U.K. Coalition government's approach to the 14-19 curriculum. The Curriculum Journal, 22(2), 265-278.

Zhang, Q., \& Stephens, M. (2013). Utilising a construct of teacher capacity to examine national curriculum reform in mathematics. Mathematics Education Research Journal, 25, 481-502. 